\section{TRICHLORETHYLENE NEUROLOGY}

\section{To the Editor:}

Doctors Noseworthy and Rice describe patients who were exposed to trichlorethylene (TCE) and made their way to a multiple sclerosis clinic. ${ }^{1}$ Several of their statements deserve comment.

1) They incorrectly suggest that the use of TCE as therapy for trigeminal neuralgia developed after it was observed that trigeminal neuropathy had occurred in the setting of TCE anesthesia. In fact, TCE was used as a treatment for trigeminal neuralgia two decades before its first use for human general anesthesia in $1935.2,3.4$

2) The statement that trichlorethylene was abandoned as an anesthetic due to "significant side effects" is misleading. In 1979, a plan to discontinue manufacture was withdrawn following protests from clinical anesthetists in the United Kingdom. ${ }^{3}$ A recent text indicates that TCE is still used as a general anesthetic in other countries. ${ }^{5}$

3) Also misleading is the sentence that, "TCE is neurotoxic." This statement leads into two descriptive paragraphs. Only later is there passing mention that dichloracetylene, a decomposition product, "may be the neurotoxic agent." In fact, pure TCE has been safely and widely used as an anesthetic both before and after any cranial neuropathy problem was reported in association with TCE anesthesia. Neurological injury following general anesthesia has occurred only in patients whose TCE was administered with an alkaloid $\mathrm{CO}_{2}$ absorber in the anesthesia circuit. The reaction of the two chemicals results in formation of phosgene and dichloracetylene which are poisonous. Avoidance of anesthesia systems with these $\mathrm{CO}_{2}$ absorbers has eliminated neurologic injury from TCE anesthesia. 5

4) Exposure to TCE breakdown products can result in severe cranial neuropathies, typically affecting the trigeminal nerves. Neither of the patients presented by Doctors Noseworthy and Rice had this characteristic bilateral trigeminal sensory neuropathy. ${ }^{2}$ Thus, the atypical neurologic symptoms of these two patients cannot be attributed with certainty to exposure to TCE or its breakdown products.

Robert Laureno, M.D. Washington Hospital Center George Washington University, School of Medicine,

Washington, D.C.

1. Noseworthy, JH and Rice, GPA. Trichlorethylene Poisoning Mimicking Multiple Sclerosis. Can J Neurol Sci 15(1): 87, 1988 (Feb.).
2. Buxton, $\mathrm{PH}$, and Hayward, $\mathrm{M}$. Polyneuritis cranialis associated with industrial trichloroethylene poisoning. J Neurol Neurosc Psychiat, 1967, 30, 511-518.

3. Coleman, J. Inhalational Anaesthetic Agent In Wylie and ChurchillDavidson's A Pract of Anaesthesia, Year Book Medical Publishers, Inc. Chicago, II. 1984.

4. Atkinson, RS. Trichlorethylene Anaesthesia. Anesthesiology, 2l(1): 67-77, 196.

5. Orkin, FK. Anesthetic Systems. In Anesthesia, Second Edition, Vol 1, Chapter 5. Churchill Livingstone, New York, Edinburg, London. 1986.

Reply

We thank Dr. Laureno for his comments.

Dr. Laureno is correct that neurologic injury should no longer occur from the use of trichlorethylene (TCE) as an anesthetic agent. Trichlorethylene is not in use as an anesthetic in North America and the precautions noted by Dr. Laureno should eliminate these problems when TCE is used in other countries.

In reporting our two cases of trichlorethylene poisoning, we focused our discussion on the consequences of industrial TCE exposure as we anticipated that such cases may have gone unrecognized by practitioners unfamiliar with this widely used solvent. There is nothing misleading about our statement that "TCE is neurotoxic". The fact that with care TCE can be used safely as a general anesthetic does not detract from the potentially serious systemic and neurological effects of industrial exposure to TCE. Although the mechanism of neurologic injury isn't completely understood, the fact remains that significant neurological injury can occur following exposure to this chemical.

Although bilateral trigeminal sensory neuropathy is perhaps the most widely recognised neurological complication of TCE exposure, as reviewed in our report (and, we think, as illustrated by one of our two cases), multiple sites in the nervous system can be damaged by TCE. Bilateral sensory trigeminal neuropathy does not occur in all cases and is not needed for the diagnosis.

Dr. Laureno is correct that TCE was first used as a treatment for trigeminal neuralgia following recognition of the occurrence of trigeminal sensory neuropathy as a result of industrial exposure to this agent.'

John H. Noseworthy, M.D. George P.A. Rice, M.D. University of Western Ontario, London, Ontario

1. Plessner W. Die Erkrankungen des Trigeminus dürch Trichlorathylenvergiftung. Monatschr. f. Psychiat. u. Neurol. 1916; 39: 120. 